\title{
A Comprehensive Update of Current Anesthesia Perspectives on Therapeutic Hypothermia
}

\author{
Ivan Urits (D) - Mark R. Jones • Vwaire Orhurhu • Andrew Sikorsky • \\ Danica Seifert · Catalina Flores · Alan D. Kaye · Omar Viswanath
}

Received: May 1, 2019 / Published online: July 12, 2019

(C) The Author(s) 2019

\begin{abstract}
Normal thermal regulation is a result of the integration of afferent sensory, central control, and efferent responses to temperature change. Therapeutic hypothermia (TH) is a technique utilized during surgery to protect vital organs from ischemia; however, in doing so leads to
\end{abstract}

Enhanced Digital Features To view enhanced digital features for this article go to https://doi.org/10.6084/ m9.figshare.8230478.

I. Urits $(\bowtie) \cdot$ M. R. Jones · V. Orhurhu

Department of Anesthesia, Critical Care, and Pain Medicine, Beth Israel Deaconess Medical Center, Harvard Medical School, Boston, MA, USA

e-mail: iurits@bidmc.harvard.edu

A. Sikorsky · D. Seifert · C. Flores

Creighton University School of Medicine, Phoenix

Regional Campus, Phoenix, AZ, USA

A. D. Kaye

Department of Anesthesiology, Louisiana State

University Health Sciences Center, New Orleans, LA, USA

O. Viswanath

Valley Anesthesiology and Pain Consultants,

Phoenix, AZ, USA

O. Viswanath

University of Arizona College of Medicine-Phoenix, Phoenix, AZ, USA

O. Viswanath

Creighton University School of Medicine, Omaha, NE, USA other physiological changes. Indications for inducing hypothermia have been described for neuroprotection, coronary artery bypass graft (CABG) surgery, surgical repair of thoracoabdominal and intracranial aneurysms, pulmonary thromboendarterectomy, and arterial switch operations in neonates. Initially it was thought that induced hypothermia worked exclusively by a temperature-dependent reduction in metabolism causing a decreased demand for oxygen and glucose. Induced hypothermia exerts its neuroprotective effects through multiple underlying mechanisms including preservation of the integrity and survival of neurons through a reduction of extracellular levels of excitatory neurotransmitters dopamine and glutamate, therefore reducing central nervous system hyperexcitability. Risks of hypothermia include increased infection risk, altered drug pharmacokinetics, and systemic cardiovascular changes. Indications for $\mathrm{TH}$ include ischemiainducing surgeries and diseases. Two commonly used methods are used to induce $\mathrm{TH}$, surface cooling and endovascular cooling. Core body temperature monitoring is essential during induction of $\mathrm{TH}$ and rewarming, with central venous temperature as the gold standard. The aim of this review is to highlight current literature discussing perioperative considerations of TH including risks, benefits, indications, methods, and monitoring. 
Keywords: Ischemia; Normal thermoregulation; Pain; Therapeutic hypothermia

\section{INTRODUCTION}

Clinical application of hypothermia has its roots in ancient times, with Greek, Romans, and Egyptians recording some of its first uses. During the nineteenth century, Baron Lerrey, Brigadiere General to Napoleon Bonaparte observed that injured soldiers who became hypothermic and were rewarmed near a fire died faster than those who remained hypothermic [1]. Normal thermal regulation is a result of the integration of afferent sensory, central control, and efferent responses to temperature change. The afferent sensors consist of thermal sensitive cells, found mostly in skin, that travel and transverse the spinal cord, and ascend to the primary thermoregulatory center in the hypothalamus. Efferent responses are dictated by threshold temperature levels in the central nervous system, and induce effects in blood flow, vasodilation, sweating, skeletal muscle tone, and overall metabolic activity. Although skin temperature deviates in parallel with patient environment, the core temperature remains a constant $98.0-98.6^{\circ} \mathrm{F}\left(37^{\circ} \mathrm{C}\right)$ even when placed in surroundings as low as $55^{\circ} \mathrm{F}$ and as high as $130^{\circ} \mathrm{F}$. There is a propensity for anesthetic drugs to disrupt this thermoregulation. Volatile anesthetics, propofol, and some opiates promote heat loss through vasodilation, while others such as fentanyl disrupt central hypothalamic regulation [2]. Indications for inducing hypothermia have been described for neuroprotection, coronary artery bypass graft (CABG) surgery, surgical repair of thoracoabdominal and intracranial aneurysms, pulmonary thromboendarterectomy, and arterial switch operations in neonates [3-9]. The aim of this review is to highlight current literature discussing perioperative considerations of $\mathrm{TH}$ including risks, benefits, indications, methods, and monitoring. This article is based on previously conducted studies and does not contain any studies with human participants or animals performed by any of the authors.

\section{NORMAL THERMOREGULATION}

Thermoregulation operates as part of homeostasis and plays a major role in preserving a stable internal state for humans to survive and maintain optimal cellular function. Normal core body temperature in humans remains around $37^{\circ} \mathrm{C}$ with the periphery $2-4{ }^{\circ} \mathrm{C}$ cooler than the core $[10,11]$. Thermoregulation is the mechanism by which the hypothalamus works to keep the body temperature at a stable level for optimal functioning [12]. To process thermal information, thermoregulation relies on three phases: afferent input, central regulation, and efferent response. The afferent input is sensed by sensors located within the epidermis and dermis with the cold signal activating myelinated $\mathrm{A} \delta$ fibers and the warm signal activating unmyelinated $C$ fibers [13]. These signals are carried along the spinothalamic tracts of the anterior spinal cord to the preoptic anterior hypothalamus to be integrated [11, 13]. The efferent response utilizes both behavioral and autonomic regulation. The behavioral component includes actions like dressing appropriately for the temperature, moving from the sun to shade, or voluntary movement and is 50\% mediated by skin temperature $[10,12]$. Autonomic regulation following a cold stimulus utilizes cutaneous vasoconstriction to reduce heat loss from convection and radiation, nonshivering thermogenesis to increase the metabolic heat production without using mechanical work seen more often in infants than adults because of their increased brown fat tissue, and shivering to increase metabolic heat production as a last response to cold [10]. As a response to heat, autonomic regulation includes vasodilation mediated by nitric oxide, and sweating mediated by postganglionic cholinergic nerves to reduce body temperature [10].

\section{PHYSIOLOGIC CHANGES WITH HYPOTHERMIA}

Therapeutic hypothermia (TH) is a technique utilized during surgery to protect vital organs from ischemia; however, in doing so it leads to other physiological changes [14]. General 
anesthesia, a form of induced hypothermia, imparts its effect on core temperature by impairing the normal thermoregulatory response causing vasodilation, inhibition of vasoconstriction, prevention of shivering, and a redistribution of heat from the core to the periphery [10]. Neuraxial anesthesia impairs thermoregulation by blocking all thermal input from the anesthetized regions and decreasing the vasoconstriction and shivering thresholds by $0.5-0.6{ }^{\circ} \mathrm{C}[10,15,16]$. Induced hypothermia results in many physiological changes, including cardiovascular, respiratory, and metabolic. After induction of general anesthesia, the decline of body temperature occurs in three phases. During the first phase, the greatest decline is seen during the first half hour and is attributed to vasodilation and a lowered cold threshold in the hypothalamus causing redistribution of body heat from the core to periphery and radiation playing a major role [2]. Phase two starts after about $1 \mathrm{~h}$ of anesthesia, and proceeds in a linear fashion with a slower rate of decrease in the core temperature due to the rate of heat loss exceeding that of heat production [2]. Phase three starts around 3-5 h, and shows a plateau in changes of core temperature indicating an equilibrium between heat loss and heat production as a result of vasoconstriction and decreased cutaneous heat loss [2, 17]. During neuraxial anesthesia, the hypothalamus may actually misinterpret skin temperature leading to the patient feeling warm when in fact they have hypothermia [2].

\section{THERAPEUTIC HYPOTHERMIA: MECHANISMS OF ACTION}

$\mathrm{TH}$ has been demonstrated to be an effective way to protect organs such as the brain, heart, and kidneys during various surgeries, as well as improve neurological outcomes following cardiac arrest, traumatic brain injuries, spinal cord injuries, stroke, or acute liver failure [18]. Initially, it was thought that induced hypothermia worked exclusively by a temperature-dependent reduction in metabolism causing a decreased demand for oxygen and glucose in the brain [19]. However, it is now known that induced hypothermia exerts its neuroprotective effects through multiple underlying mechanisms. When the brain experiences a decrease in oxygen and blood flow causing an ischemic injury, a cascade follows that may ultimately result in an increase in extracellular glutamate and increase in NMDA responsiveness producing neuronal cell death [18]. TH works to maintain and preserve the integrity and survival of these neurons by reducing extracellular levels of excitatory neurotransmitters, e.g., dopamine and glutamate, thereby reducing central nervous system hyperexcitability. The release of both is temperature dependent with lower temperatures inhibiting their release $[18,20]$. Glycine is required for NMDA receptors to be activated, so an increase in glycine accelerates the function of NMDA receptors. TH depletes glycine brain levels preventing hyperexcitability of NMDA receptors by glutamate [18]. Hypothermia also protects organs from ischemic injury by reducing cerebral blow flow, the metabolic rate, and oxygen and glucose consumption. The decrease in cerebral metabolic demands results in slower enzyme activity allowing for ATP stores to be preserved [20]. Normally when ischemic injury occurs, cells can partially or fully recover, become necrotic, or can enter into a programmed cell death called apoptosis. Studies in the past have shown that $\mathrm{TH}$ is able to interrupt apoptosis as early as initiation. TH exerts its effects on apoptosis by inhibiting caspase activity, increasing antiapoptotic Bcl-2 expression, and preventing mitochondrial dysfunction [18-20]. Another mechanism by which $\mathrm{TH}$ provides neuroprotection is through the reduction of free radical formation that follows ischemia [18-20]. Hypothermia additionally decreases consumption of endogenous antioxidants. With less free radicals and the presence of antioxidants, the body is able to mitigate the oxidative damage that free radicals induce, allowing more cells to repair and recover [19]. It has been shown that TH may interfere with the activity of superoxide dismutase, leading to less hydrogen peroxide and fewer hydroxyl radicals [20]. The last proposed mechanism that TH works by is preserving collagen integrity by decreasing interstitial collagen fragmentation, increasing protein 
survival, and promoting signals to allow for cell survival. TH may increase myocardial blood flow, improve microvascular integrity, and reduce myocardial energy utilization during ischemia leading to improved viability and myocardial function [21]. TH has both benefits and drawbacks in terms of physiological changes that occur when it is employed making it necessary to understand the mechanisms of action by which it works. The mechanisms by which TH imparts protective effects are summarized in Table 1.

\section{RISKS OF PERIOPERATIVE HYPOTHERMIA}

The potential risks associated with perioperative hypothermia have been extensively studied and can be classified into several broad categories (Table 2). Coagulopathic concerns in perioperative hypothermia include impaired platelet aggregation and increased blood loss. Inhibition of platelet aggregation in the setting of

Table 1 Mechanisms of action for therapeutic hypothermia

\begin{tabular}{|c|c|}
\hline Neurotransmitters & $\begin{array}{l}\text { Reduces extracellular levels of } \\
\text { glutamate and glycine }\end{array}$ \\
\hline Metabolism & $\begin{array}{l}\text { Reduces cerebral blood flow, } \\
\text { metabolic rate, and oxygen } \\
\text { and glucose consumption }\end{array}$ \\
\hline Apoptosis & $\begin{array}{l}\text { Inhibits apoptosis through } \\
\text { decrease caspase activity, } \\
\text { increased Bcl-2 expression, } \\
\text { and prevention of } \\
\text { mitochondrial dysfunction }\end{array}$ \\
\hline Free radicals & $\begin{array}{l}\text { Reduces free radical formation } \\
\text { and decreases consumption of } \\
\text { endogenous antioxidants }\end{array}$ \\
\hline $\begin{array}{l}\text { Collagen integrity and } \\
\text { myocardial function }\end{array}$ & $\begin{array}{l}\text { Decreases interstitial collagen } \\
\text { fragmentation and myocardial } \\
\text { energy utilization during } \\
\text { ischemia }\end{array}$ \\
\hline
\end{tabular}

Table 2 Risks of perioperative hypothermia

\begin{tabular}{|c|c|}
\hline Coagulopathies & $\begin{array}{l}\text { Impaired platelet aggregation } \\
\text { Increased blood loss }\end{array}$ \\
\hline Increased infection risk & $\begin{array}{l}\text { Direct reduction of immune cell } \\
\text { function } \\
\text { Vasoconstriction } \\
\text { Impaired tissue healing }\end{array}$ \\
\hline $\begin{array}{l}\text { Plasma solute } \\
\text { concentration } \\
\text { alterations }\end{array}$ & $\begin{array}{l}\text { Hyperglycemia } \\
\text { Hypokalemia }\end{array}$ \\
\hline Pharmacokinetics & $\begin{array}{l}\text { Decreased clearance (muscle } \\
\text { relaxant, volatile anesthetic, } \\
\text { opiate anesthetic, and } \beta \text { - } \\
\text { adrenoceptor agonists) }\end{array}$ \\
\hline Cardiovascular & $\begin{array}{l}\text { Hypotension } \\
\text { Bradycardia } \\
\text { Arrythmias } \\
\text { Myocardial demand } \\
\text { Catecholamine release } \\
\text { ECG changes (QTc } \\
\text { prolongation, PR interval } \\
\text { prolongation, QRS } \\
\text { prolongation) }\end{array}$ \\
\hline Rebound hyperthermia & $\begin{array}{l}\text { Shivering } \\
\text { Cold-induced diuresis }\end{array}$ \\
\hline
\end{tabular}

hypothermia has been demonstrated both in vivo and in vitro [10]. Platelet activation in normal volunteers demonstrates inhibition of platelet aggregation at hypothermic temperatures, through both impaired release of thromboxane $A_{2}$, which is necessary for the initial plug formation, and enzymes in the coagulation cascade. Notably, these inhibitory effects of hypothermia were all completely reversed by rewarming the blood to $37^{\circ} \mathrm{C}$ [22]. Mildly hypothermic temperatures seem to lead to increased blood loss. In one systematic review of blood loss in mildly hypothermic patients, 
the relative risk for transfusion increased by approximately $22 \%$, and a single degree Celsius significantly increases blood loss by approximately $16 \%$ [23].

Hypothermia has been shown to induce mechanisms for increased infection risk including vasoconstriction, impaired tissue healing, and reduced immune cell function. In vitro models demonstrate significant impairments in human peripheral polymorphonuclear leukocyte chemotaxis, phagocytic engulfment, phagocytic digestion, and oxygen consumption in temperatures less than $37^{\circ} \mathrm{C}$ [24]. Clinical effects of hypothermia include decreased white blood cell counts, as well as suppression of hyperinflammatory responses [25]. Sympathetic stimulation causes vasoconstriction in skin, arms, and legs leading to diminished skin and extremity blood flow, thus potentially increasing risk for bed sores and surgical site infection [19]. Perioperative hypothermia prolongs postoperative catabolism, and inhibits deposition of collagen, thus contributing to impaired tissue healing [26]. The link between perioperative hypothermia and increased wound infection rates has been demonstrated in multiple surgical settings, which include trauma laparotomy, colorectal resection, hernia repair, varicose vein ablation, and breast surgery [27-30].

Electrolyte disturbances during perioperative hypothermia include a compartmental shift of potassium ions, leading to hypokalemia as low as $2.3 \pm 0.4 \mathrm{mEq} / \mathrm{l}$ observed in some patients $[31,32]$. Similarly, intracellular shifting of magnesium and phosphate should be monitored. Additional solute shifts encountered during hypothermia include hyperglycemia, whereby lowering of basal body temperature impairs insulin release, increasing glucose levels, leading to impairment of leukocyte function and thus decreased immunity [25]. Alterations in the absorption of the ascending loop of Henle, as well as systemic vasoconstriction leading to reflex diuresis, are thought to contribute to cold-induced diuresis seen in some patients, necessitating the vigilant monitoring of volume status [33].

It has been shown that hypothermia increases drug concentration and prolongs drug response in multiple clinical and animal studies. Numerous mechanisms contribute to reduced hepatic drug clearance including reduction in blood flow, alterations in the plasma protein and drug binding properties, and intrinsic enzymatic rate fluctuations. Similarly, changes observed in renal filtration, active secretion, and absorption all contribute to the altered pharmacokinetics in hypothermic patients [34].

Hypothermia impacts the pharmacological effect of muscle relaxants, volatile anesthetics, opiate anesthetics, and $\beta$-adrenoceptor agonists. Heier et al. reported that the duration of action of and time to spontaneous recovery from vecuronium-induced muscle blockade increased in the setting of $34.5^{\circ} \mathrm{C}$ [35]. Leslie et al. demonstrated that, in the setting of $34^{\circ} \mathrm{C}$, atracurium duration of action was significantly increased in healthy volunteers [36]. In regards to volatile anesthetics, decreases in isoflurane requirements have been observed in children as temperature decreases, from $1.69 \pm 0.14 \%$ at $37^{\circ} \mathrm{C}$ to $1.22 \pm 0.5 \%$ at $31^{\circ} \mathrm{C}$, theorized to be an effect from the reduction in CYP2E1 activity seen in reduced temperatures [37]. Puig et al. demonstrated that the effectiveness of morphine significantly decreased at $30^{\circ} \mathrm{C}$ as compared to $40^{\circ} \mathrm{C}$ in pig ileum, while in another study a single $1 \mathrm{mg} / \mathrm{kg}$ bolus injection of morphine in dogs led to significant decrease in mean arterial pressure in hypothermia but not in normothermia $[38,39]$. $\beta$-Adrenergic mediated cardiovascular responses have been shown to be significantly blunted when core temperatures were kept at $33^{\circ} \mathrm{C}$ [40].

Cardiovascular effects of hypothermia include systemic hypotension, bradycardia, and prolongation of the QTc interval. Therapeutic hypothermia has been positively associated with a prolongation of the QTc (>460 ms), increasing risk for ventricular fibrillation and ventricular tachycardia independently [41]. Increased catecholamine levels seen in hypothermic patients can lead to increased myocardial oxygen demand and cardiac output. Common ECG changes observed include increased PR interval, QRS widening, and J-wave appearance, with subsequent significant increases in arrhythmias such as atrial 
fibrillation and ventricular fibrillation when temperatures are reduced below $30{ }^{\circ} \mathrm{C}[33,42]$.

Shivering can be induced in patients with core temperature reductions as low as $0.5^{\circ} \mathrm{C}$. This physiological stressful event is triggered through increased neuronal efferent outflow to skeletal muscle and feedback oscillations due to spindle stretch reflexes, leading to involuntary oscillatory movements [2]. Therapeutic interventions to prevent shivering and its complications (increased metabolic rate, oxygen consumption, and $\mathrm{CO}_{2}$ production leading to acidosis) include alpha-2 agonists (clonidine, dexmetatomidine) that lead to reduced sympathetic activity and central regulation of vasoconstrictor tone, as well as meperidine, mechanistically thought to be induced through kappa opiate anti-shivering properties [43, 44].

After the conclusion of the hypothermic period, the phenomenon of rebound hypothermia is an independent predictor of increased mortality and neurologic morbidity in cardiac arrest patients who have undergone therapeutic hypothermia [33, 45].

\section{OPERATIVE INDICATIONS FOR THERAPEUTIC HYPOTHERMIA}

The development of postoperative cognitive deficits is a relatively common complication of cardiac surgery, thought to arise from temporary brain ischemia. Overall, evidence for intraoperative and postoperative cooling is conflicting; however, much of the evidence suggests that $\mathrm{TH}$ can play a role in neuroprotection [1]. Studies have shown that achieving core temperatures of $32-36^{\circ} \mathrm{C}$ minimizes adverse effects associated with hypothermia while maximizing neuroprotection. Deep hypothermic circulatory arrest (DHCA) is a technique used to completely halt circulation and brain function; it is used primarily for procedures with high risk of intraoperative hemorrhage. Applications include aortic arch repairs and resection of tumors invading the vena cava [20]. During DHCA, cardiopulmonary bypass (CBP) can be coupled with either selective antegrade cerebral perfusion (SACP) or retrograde cerebral perfusion (RCP). Both approaches increase the safety of DHCA [46]. The complete cessation of blood flow enables thorough heart visualization and decreased risk of embolization [20].

As a result of its practice in cardiac surgery, studies have explored $\mathrm{TH}$ use in neurosurgical candidates-particularly in patients who have sustained traumatic brain injury (TBI), intracranial hemorrhage, or stroke. Hypothermia imparts a neuroprotective role; every degree decrease in core body temperature decreases cerebral metabolism by $5 \%$. TH has also been found to induce burst suppression on EEG, a pattern which indicates an inactivated brain state. Despite this, $\mathrm{TH}$ has no effect on decreasing mortality, neurologic disability, intraoperative hemorrhage, or postoperative incidence of myocardial infarction. There is some evidence to suggest a decrease in infective complications [47]. Further investigation is required to establish $\mathrm{TH}$ as a viable means for improving patient outcomes during neurosurgery [47].

Open surgical repair of aortic aneurysms requires clamping of the aorta which can lead to organ ischemia and reperfusion injury, particularly in the kidneys and colon. Colonic injury is most common with infrarenal abdominal aortic aneurysm (AAA) repairs, since the inferior mesenteric artery (IMA) may be compromised. Pharmacotherapy has shown little efficacy in reducing mortality. Post-conditioning-gradually increasing blood flow after clamping-may reduce reperfusion injury, particularly in infrarenal repairs. In suprarenal repairs, cold renal perfusion has been shown to be a more practical and effective approach $(300 \mathrm{~mL}$ bolus followed by continuous perfusion of $20 \mathrm{~mL} / \mathrm{min}$ hypothermic saline at $4{ }^{\circ} \mathrm{C}$ through a renal artery catheter) [48].

The Prophylactic hypOthermia to Lessen trAumatic bRain injury-Randomized Controlled Trial (POLAR-RCT) is a phase III trial that is currently underway. The study includes 511 patients in Australia, New Zealand, France, Switzerland, Saudi Arabia, and Qatar enrolled with severe acute TBI. It will determine if prophylactic hypothermia to $33^{\circ} \mathrm{C}$ for $72 \mathrm{~h}$ will have a larger impact on long-term outcomes compared to normothermic conditions [49]. 
Current data inconsistently shows its effectiveness.

\section{NONOPERATIVE INDICATIONS}

Cardiac arrest is a leading cause of mortality in the USA. Studies have suggested that cerebral ischemia not only occurs during cardiac arrest and resuscitation but may also persist for several hours afterward as a result of reperfusion injury [1]. Therefore, achieving temperatures of $32-36{ }^{\circ} \mathrm{C}$ within the first few hours following cardiac arrest has been shown to decrease neurologic injury and mortality in select patients. Rapid initiation of $\mathrm{TH}$ and maintenance for at least $48 \mathrm{~h}$ is recommended for patients unresponsive to verbal commands [50].

Although animal studies have found $\mathrm{TH}$ to be an effective treatment for TBI, clinical trials have been less conclusive. Indeed, TH is effective in reducing intracranial pressures; however, it does not appear to effect patient outcomes [1]. Therefore, it should not be used as a primary treatment modality and instead be used for patients with refractory cases of increased intracranial pressures [51]. Spinal cord injuries involve a primary insult, followed by a secondary inflammatory cascade that induces further damage. $\mathrm{TH}$ has been shown, in animal models, to reduce secondary damage from ischemia, oxidative stress, apoptosis, inflammation, and edema. There is some evidence of similar outcomes in clinical trials, but further studies are needed to reach a conclusion [52]. Although not thoroughly investigated, some case reports have described successful use of TH in the treatment of refractory status epilepticus. Animal models have demonstrated that focal cooling may be useful in aborting seizures [53]. However, a recent randomized trial showed no significant effect on long-term patient outcomes compared to standard treatment [54].

\section{METHODS OF INDUCING HYPOTHERMIA}

Two methods are commonly used to induce TH, surface cooling and endovascular cooling.
Surface cooling can be achieved via utilization of cooling blankets (both air- and water-circulating types are available), sponge baths, ice packs, pads, wrapping garments, and Arctic Sun (a hydrogel-coated water-circulating pad) [55]. Although originally used in the treatment of fever [56], its accessibility also makes it a practical option for the prehospital setting; however, there are several disadvantages that limit its use [55]. Achieving target temperaturesparticularly in obese patients-is slower than endovascular cooling [20]. Additionally, its lack of precision can lead to overcooling and complications with rewarming, increasing the risk of cerebral edema [56]. Surface cooling methods are also more likely to induce shivering, therefore necessitating analgesia and neuromuscular blockade [50]. Rarely, skin irritation and burns can occur [55].

Endovascular methods include cold saline infusion and saline-filled balloons. This approach generally reduces many of the risks associated with surface cooling, but may cause catheter-associated bloodstream infections, require more advanced medical training, and are more expensive [55].

There is currently no evidence in the literature that suggests superiority of any cooling method. Therefore, physicians should utilize methods that are readily available and familiar. In practice, a combination of surface cooling and intravascular cooling is often used to achieve desired temperatures [50].

Hypothermic cardiopulmonary bypass plays an important role during cardiac surgeries. In achieving intraoperative core temperatures of $32-36^{\circ} \mathrm{C}$, most of the adverse effects of hypothermia are avoided while providing appropriate neuroprotection [20]. Changes in blood/gas solubility may affect anesthesia requirements, necessitating the use of special monitoring [20].

\section{MONITORING}

Core body temperature monitoring is essential during induction of $\mathrm{TH}$ and rewarming, with central venous temperature as the gold standard. During rewarming, incremental increases 
of $0.2-0.25^{\circ} \mathrm{C} / \mathrm{h}$ should be achieved in order to avoid complications such as electrolyte abnormalities, cerebral edema, and seizures [50]. If a pulmonary artery catheter is in place, pulmonary arterial blood temperature can be monitored. Temperature monitoring can also be accomplished via distal esophagus, nasopharynx, and tympanic membrane probes. Nasopharyngeal and esophageal probes are commonly used during general anesthesia [56], with esophageal temperatures being the most accurate. Tympanic membrane probes are fairly accurate devices, but must be differentiated from tympanic membrane infrared scanners which should not be used [50].

There are two types of strategies for monitoring acid-base status during TH: alpha-stat and $\mathrm{pH}$-stat. Alpha-stat is independent of patient core temperature, with arterial $\mathrm{PaCO}_{2}$ and $\mathrm{pH}$ set at normothermic values $(40 \mathrm{mmHg}$ and 7.4 , respectively). In contrast, $\mathrm{pH}$-stat is corrected on the basis of patient temperature. Therefore, $\mathrm{pH}$-stat results in increased $\mathrm{PaCO}_{2}$ values and decreased $\mathrm{pH}$ values compared to the alpha-stat approach; increased $\mathrm{PaCO}_{2}$ levels are analogous to cerebral vasodilation, $\mathrm{pH}$-stat management portrays increased cerebral blood flow $[46,56]$. The concern with the use of $\mathrm{pH}-$ stat is a loss of autoregulation in the brain which can lead to cerebral microembolization and increased intracranial pressures [56]. Clinically, it has been shown that $\mathrm{pH}$-stat monitoring is more useful for deep hypothermia, while alpha-stat is more useful for moderate hypothermia [57]. Still there remains debate over superiority of one method over the other [50].

\section{CONCLUSION}

Thermoregulation operates as part of homeostasis and plays a major role in preserving a stable internal state for humans to survive and maintain optimal cellular function. Clinically induced therapeutic hypothermia is an integral intervention for the preservation of end organ and neuronal function during ischemia-inducing surgeries and patient conditions. Induction of hypothermia can be achieved via systemic or intravascular cooling modalities.

\section{ACKNOWLEDGEMENTS}

Funding. No funding or sponsorship was received for this study or publication of this article.

Authorship. All named authors meet the International Committee of Medical Journal Editors (ICMJE) criteria for authorship for this article, take responsibility for the integrity of the work as a whole, and have given their approval for this version to be published.

Disclosures. Ivan Urits, Mark R. Jones, Vwaire Orhurhu, Andrew Sikorsky, Danica Seifert, Catalina Flores, Alan D. Kaye and Omar Viswanath have nothing to disclose.

Compliance with Ethics Guidelines. This article is based on previously conducted studies and does not contain any studies with human participants or animals performed by any of the authors.

Open Access. This article is distributed under the terms of the Creative Commons Attribution-NonCommercial 4.0 International License (http://creativecommons.org/licenses/ by-nc/4.0/), which permits any noncommercial use, distribution, and reproduction in any medium, provided you give appropriate credit to the original author(s) and the source, provide a link to the Creative Commons license, and indicate if changes were made.

\section{REFERENCES}

1. Polderman KH. Application of therapeutic hypothermia in the ICU: opportunities and pitfalls of a promising treatment modality. Part 1: indications and evidence. Intensive Care Med. 2004;30(4):556-75. 
2. Díaz M, Becker DE. Thermoregulation: physiological and clinical considerations during sedation and general anesthesia. Anesth Prog. 2010;57(1):25-32.

3. Ali Aydemir N, et al. Randomized comparison between mild and moderate hypothermic cardiopulmonary bypass for neonatal arterial switch operation. Eur J Cardiothorac Surg. 2012;41(3):581-6.

4. Boodhwani M, Rubens FD, Wozny D, Nathan HJ. Effects of mild hypothermia and rewarming on renal function after coronary artery bypass grafting. Ann Thorac Surg. 2009;87(2):489-95.

5. Bush HL, et al. Hypothermia during elective abdominal aortic aneurysm repair: the high price of avoidable morbidity. J Vasc Surg. 1995;21(3):392-402.

6. Conolly S, Arrowsmith JE, Klein AA. Deep hypothermic circulatory arrest. Contin Educ Anaesth Crit Care Pain. 2010;10(5):138-42.

7. Griepp RB, Di Luozzo G. Hypothermia for aortic surgery. J Thorac Cardiovasc Surg. 2013;145(3):S56-8.

8. Nguyen HP, et al. Perioperative hypothermia $\left(33^{\circ} \mathrm{C}\right)$ does not increase the occurrence of cardiovascular events in patients undergoing cerebral aneurysm surgery: findings from the intraoperative hypothermia for aneurysm surgery trial. Anesthesiology. 2010;113(2):327-42.

9. Todd MM, et al. Mild intraoperative hypothermia during surgery for intracranial aneurysm. N Engl J Med. 2005;352(2):135-45.

10. Bindu B, Bindra A, Rath G. Temperature management under general anesthesia: compulsion or option. J Anaesthesiol Clin Pharmacol. 2017;33(3):306-16.

11. Morrison SF, Nakamura K. Central mechanisms for thermoregulation. Annu Rev Physiol. 2018;12:57.

12. Osilla EV, Sharma S. StatPearls physiology, temperature regulation. Treasure Island: StatPearls; 2018.

13. Romanovsky AA. Thermoregulation: some concepts have changed. Functional architecture of the thermoregulatory system. Am J Physiol Regul Integr Comp Physiol. 2007;292(1):R37-46.

14. Wong KC. Physiology and pharmacology of hypothermia. West J Med. 1983;138(2):227-32.

15. Ozaki M, et al. Thermoregulatory thresholds during epidural and spinal anesthesia. Anesthesiology. 1994;81(2):282-8.
16. Shaw CA, Steelman VM, Deberg J, Schweizer ML. Effectiveness of active and passive warming for the prevention of inadvertent hypothermia in patients receiving neuraxial anesthesia: a systematic review and meta-analysis of randomized controlled trials. J Clin Anesth. 2017;38:93-104.

17. Kurz A, Sessler DI, Christensen R, Dechert M. Heat Balance and Distribution during the Core-Temperature Plateau in Anesthetized Humans. Anesthesiology. 1995;83(3):491-9.

18. González-Ibarra FP, Varon J, López-Meza EG. Therapeutic hypothermia: critical review of the molecular mechanisms of action. Front Neurol. 2011;2:4.

19. Polderman KH. Mechanisms of action, physiological effects, and complications of hypothermia. Crit Care Med. 2009;37(Suppl):S186-202.

20. Otto KA. Therapeutic hypothermia applicable to cardiac surgery. Vet Anaesth Analg. 2015;42(6):559-69.

21. Ning $\mathrm{X}-\mathrm{H}$, et al. Moderate hypothermia $\left(30^{\circ} \mathrm{C}\right)$ maintains myocardial integrity and modifies response of cell survival proteins after reperfusion. Am J Physiol Heart Circ Physiol. 2007;293(4):H2119-28.

22. Michelson $\mathrm{AD}$, et al. Reversible inhibition of human platelet activation by hypothermia in vivo and in vitro. Thromb Haemost. 1994;71(5):633-40.

23. Rajagopalan S, Mascha E, Na J, Sessler DI. The effects of mild perioperative hypothermia on blood loss and transfusion requirement. Anesthesiology. 2008;108(1):71-7.

24. van Oss CJ, et al. Effect of temperature on the chemotaxis, phagocytic engulfment, digestion and $\mathrm{O} 2$ consumption of human polymorphonuclear leukocytes. J Reticuloendothel Sox. 1980;27(6):561-5.

25. Polderman KH. Is therapeutic hypothermia immunosuppressive? Crit Care. 2012;16(Suppl 2):A8.

26. Rintamäki H. Human responses to cold. Alaska Med. 2007;49(2 Suppl):29-31.

27. Flores-Maldonado A, Medina-Escobedo CE, RíosRodríguez HM, Fernández-Domínguez R. Mild perioperative hypothermia and the risk of wound infection. Arch Med Res. 2001;32(3):227-31.

28. Hedrick TL, et al. Efficacy of protocol implementation on incidence of wound infection in colorectal operations. J Am Coll Surg. 2007;205(3):432-8. 
29. Pietsch AP, Lindenblatt N, Klar E. Perioperative hypothermie. Der Anaesthes. 2007;56(9):936-9.

30. Seamon MJ, et al. The effects of intraoperative hypothermia on surgical site infection. Ann Surg. 2012;255(4):789-95.

31. Koht A, Cane R, Cerullo LJ. Serum potassium levels during prolonged hypothermia. Intensive Care Med. 1983;9(5):275-7.

32. Zydlewski AW, Hasbargen JA. Hypothermia-induced hypokalemia. Mil Med. 1998;163(10):719-21.

33. Luscombe M, Andrzejowski JC. Clinical applications of induced hypothermia. Contin Educ Anaesth Crit Care Pain. 2006;6(1):23-7.

34. Zhou J, Poloyac SM. The effect of therapeutic hypothermia on drug metabolism and response: cellular mechanisms to organ function. Expert Opin Drug Metab Toxicol. 2011;7(7):803-16.

35. Heier T, Caldwell JE, Sessler DI, Miller RD. Mild intraoperative hypothermia increases duration of action and spontaneous recovery of vecuronium blockade during nitrous oxide-isoflurane anesthesia in humans. Anesthesiology. 1991;74(5):815-9.

36. Leslie K, Sessler DI, Bjorksten AR, Moayeri A. Mild hypothermia alters propofol pharmacokinetics and increases the duration of action of atracurium. Anesth Analg. 1995;80(5):1007-14.

37. Liu M, Hu X, Liu J. The effect of hypothermia on isoflurane $\mathrm{MAC}$ in children. Anesthesiology. 2001;94(3):429-32.

38. Bansinath $\mathrm{M}$, Turndorf $\mathrm{H}$, Puig MM. Influence of hypo and hyperthermia on disposition of morphine. J Clin Pharmacol. 1988;28(9):860-4.

39. Puig MM, et al. Effects of temperature on the interaction of morphine with opioid receptors. Br J Anaesth. 1987;59(11):1459-64.

40. Han Y-S, et al. Changes in cardiovascular $\beta$ adrenoceptor responses during hypothermia. Cryobiology. 2008;57(3):246-50.

41. Khan JN, Prasad N, Glancy JM. QTc prolongation during therapeutic hypothermia: are we giving it the attention it deserves? Europace. 2010;12(2):266-70.

42. Soleimanpour H, Rahmani F, Golzari SE, Safari S. Main complications of mild induced hypothermia after cardiac arrest: a review article. J Cardiovasc Thorac Res. 2014;6(1):1-8.

43. Eydi M, et al. Postoperative management of shivering: a comparison of pethidine vs. ketamine. Anesthesiol Pain Med. 2014;4(2):e15499.
44. Lewis SR, Nicholson A, Smith AF, Alderson P. Alpha-2 adrenergic agonists for the prevention of shivering following general anaesthesia. Cochrane Database Syst Rev. 2015;8:107.

45. Raper JD, Wang HE. Urine output changes during postcardiac arrest therapeutic hypothermia. Ther Hypoth Temp Manag. 2013;3(4):173-7.

46. Cheung AT. Anesthesia for aortic surgery requiring deep hypothermia - UpToDate [Internet]. UpToDate. 2019. p. 1.

47. Galvin IM, et al. Cooling for cerebral protection during brain surgery. Cochrane Database of Syste Rev. 2015;(1):CD006638.

48. Yeung $\mathrm{KK}$, et al. Organ protection during aortic cross-clamping. Best Pract Res Clin Anaesthesiol. 2016;30(3):305-15.

49. Presneill J, et al. Statistical analysis plan for the POLAR-RCT: the Prophylactic hypOthermia trial to Lessen trAumatic bRain injury-Randomised Controlled Trial. Trials. 2018;19(1):259.

50. Rittenberger JC, Callaway CW. Post-cardiac arrest management in adults - UpToDate [Internet]. UpToDate. 2019. p. 1.

51. Rajajee V. Management of acute severe traumatic brain injury - UpToDate [Internet]. UpToDate. 2019. p. 1.

52. Alkabie S, Boileau AJ. The role of therapeutic hypothermia after traumatic spinal cord injury-a systematic review. World Neurosurg. 2016;86:432-49.

53. Karkar KM, et al. Focal cooling suppresses spontaneous epileptiform activity without changing the cortical motor threshold. Epilepsia. 2002;43(8):932-5.

54. Legriel S, et al. Hypothermia for neuroprotection in convulsive status epilepticus. $\mathrm{N}$ Engl J Med. 2016;375(25):2457-67.

55. Vaity C, Al-Subaie N, Cecconi M. Cooling techniques for targeted temperature management postcardiac arrest. Crit Care. 2015;19(1):1-6.

56. Song SS, Lyden PD. Overview of therapeutic hypothermia. Curr Trea Opt Neurol. 2012;14(6):541-8.

57. Baraka A. Alpha-stat vs. pH-stat strategy during hypothermic cardiopulmonary bypass. Middle East J Anaesthesiol. 2004;17(4):705-12. 